\title{
Determination of inhalation toxicity of the ozone-air mixture
}

\author{
Valery Belyaev ${ }^{1, *}$, Vladimir Nikulin ${ }^{1}$, Ruslan Kochkarov ${ }^{1}$, Nikolay Gvozdetsky ${ }^{1}$, and Elena \\ Grudeva $^{1}$ \\ ${ }^{1}$ Stavropol State Agrarian University, 357017, Stavropol, Russia
}

\begin{abstract}
The work on the inhalation toxicity of the ozone-air mixture was carried out in two stages. At the first stage, acute inhalation toxicity was studied and the class of toxicity was determined, at the second stage, subchronic inhalation toxicity was determined. The object of the study was an ozone-air mixture. A portable standalone ozone generation device developed by us was used as a source of the mixture. A total of 58 outbred mature white Wistar rats of both sexes were used in the study, where 18 rats participated in the first stage, and 40 rats in the second. The animals were placed in an inhalation chamber. The procedure for testing acute inhalation toxicity was carried out according to the standard method at concentrations of ozone-air mixture of 100, 500, $2500 \mathrm{ppm}$ and an exposure of 4 hours. As a result, the fatal outcome was observed only in 3 groups ( $2500 \mathrm{ppm}), 3$ out of 6 individuals were killed, including 2 males and 1 female. In fallen animals, death occurred as a result of respiratory arrest. The surviving animals were monitored for 14 days after the test. During the treatment of animals with ozone-air mixture, a gradual inhibition of the respiratory system was observed, followed by the development of pulmonary edema and respiratory failure. Based on the data obtained, the ozone-air mixture under study was assigned a hazard class 3. In the study of subchronic inhalation toxicity of oats, concentrations of 250,125 , and $50 \mathrm{ppm}$ were studied. The experiment was carried out, according to the standards for determining the subchronic inhalation toxicity of substances, for 90 days. During the experiment, body weight, feed consumption, behavioral activity were recorded, and blood hematological and biochemical parameters were determined. As a result of the study of subchronic inhalation toxicity of the ozone-air mixture, no signs of intoxication were detected in rats, and there were no death cases.
\end{abstract}

\section{Introduction}

At the present stage of development of veterinary science, the use of ozone is gaining popularity, both for therapeutic purposes [1-8] and in many preventive measures [8-14]. The intensive development of ozone therapy opens up more and more prospects for the use of ozone in the treatment of various diseases, both in humans and in animals. One of the key mechanisms of the therapeutic effect of ozone on the macroorganism is the moderate

* Corresponding author: valstavvet@yavdex.ru 
activation of lipid peroxidation (LOP) [14], accompanied by compensatory strengthening of the body's antioxidant systems. It should be noted that free radical reactions of lipid peroxidation play a significant role in the normal physiology of the cell and are necessary for the course of certain metabolic processes. For example, LOP metabolites within 10 $\mathrm{nmol} / \mathrm{mg}$ regulate the recovery of nerve tissue after arousal.[15, 16]

This efficiency of action caused an increase in offers on the market of industrial, medical, and household ozonators. Often, the raw material for producing ozone is atmospheric air, as a more accessible source of oxygen, which leads to the appearance of additional impurities in the resulting gas mixture. [17-20] the high activity of ozone as a disinfectant is associated with its strong oxidative properties, which cause its high toxicity for macroorganisms [21, 22]. Therefore, the key role in working with ozone is to determine the concentrations of ozone-containing gas mixtures that are safe for humans and animals and the conditions for their use.

The aim of this work is to study the acute inhalation and subchronic inhalation toxicity of an ozone-air mixture obtained on a portable standalone ozone generation device of its own design, and to determine its toxicity class. токсичности.

\section{Materials and methods}

The object of the study is an ozone-air mixture. A portable standalone barrier-type ozone generation device (patent for the invention) was used as the source of this mixture RUS 2661232 IPC C01B 13/11. 13.07.2018).

Outbred mature rats of both sexes of the Wistar line were used in the experiments (weight of females 140-150 g, males 150-170 g). The animals were kept in polycarbonate cages with a lattice cover.

The research took place in an inhalation chamber, where cages with experimental rats were placed. Critical indicators such as the concentration of oxygen (at least 19\%) and carbon dioxide (not exceeding 1\%) were monitored. The temperature in the chamber was maintained at $21-23^{\circ} \mathrm{C}$.

Animal maintenance and experiments were carried out in accordance with article 5 "Guidelines for the maintenance and care of laboratory animals" of the European Convention on the protection of vertebrates used for experimental or other scientific purposes "(Strasbourg, 1986), as well as in accordance with the Federal law of the Russian Federation "of the state's animal cruelty statutes ". 01.01.1997 г.

The scheme for the study of acute inhalation toxicity was compiled in accordance with the Russian state standard 32646-2014 "acute inhalation toxicity-method for determining the class of acute toxicity (ATS method)". For the experiment, a total of 18 rats were used, divided into 3 experimental groups, 6 individuals each ( 3 males and 3 females). For the testing procedure, the initial concentration of the ozone-air mixture of $100 \mathrm{mg}$ (group 1) was selected, which, in accordance with the scheme of the experiment, was then increased to $500 \mathrm{mg}$ (group 2) and $2500 \mathrm{mg} / \mathrm{kg}$ (group 3). [5] animal observations were made within 14 days after the test. We took into account the appearance and behavior of animals, the condition of the coat and visible mucous membranes, the attitude to food and water, mobility and sensitivity to external stimuli, the rhythm and frequency of breathing and heartbeat.

The scheme for the study of subchronic inhalation toxicity is compiled in accordance with the state standard of the Russian Federation 32636-2014."Subchronic inhalation toxicity: a 90-day study", and in accordance with the MP-534-2009 standard "principles of good laboratory practice". In the experiment, 40 rats were used, which were divided into three experimental and one control groups, 10 rats each, including 5 males and 5 females. The test groups of animals were exposed to the ozone-air mixture at the specified 
concentration (group 1-250 mg, group 2-125 mg, group 3-50 mg) for 6 hours 5 days a week for 13 weeks. Individuals of the control group were kept under the same conditions, except for exposure to the ozone-air mixture.

Measurement of body weight of rats was performed on mercury M-ER laboratory scales once a week throughout the study.

During the experiment, the general condition of the rats was observed (appearance, condition of the coat and skin, presence of salivation, lacrimation), the consumption of food and water, and the dynamics of body weight were recorded.

The biochemical analysis of rat blood was performed on the iMagic-V7, veterinary automatic biochemical analyzer, and the hematological study was performed on the veterinary hematological analyzer Mindray BC-2800Vet.

The study of behavioral activity of rats was carried out using the "open field" method [2], in which the animal is placed in the central square of the installation and monitored for 2 minutes. Animals were tested once. When analyzing the results, we took into account the number of intersected peripheral and central squares, peripheral and central racks, and also recorded the number of climbing into holes, grooming, acts of defecation (by the number of boluses), and the latent period of the first movement. After testing, the animal was placed back in the cage, and the surface of the field was thoroughly washed before examining the next rat. To calculate the level of the main activity of each individual, the number of peripheral and central squares and racks crossed by it was summed up.

The obtained research results were subjected to statistical processing in the program Statistica 6.0. The arithmetic mean (M) and standard error of the mean (m) were calculated from the number of elements of descriptive statistics).

\section{Research result}

\subsection{Acute inhalation toxicity}

The results of a series of experiments on the inhalation effects of an ozone-air mixture on three experimental groups of rats are shown in figure 1. According to the method used, the concentrations were 100, 500 and $2500 \mathrm{ppm}$ of the ozone-air mixture, respectively. 


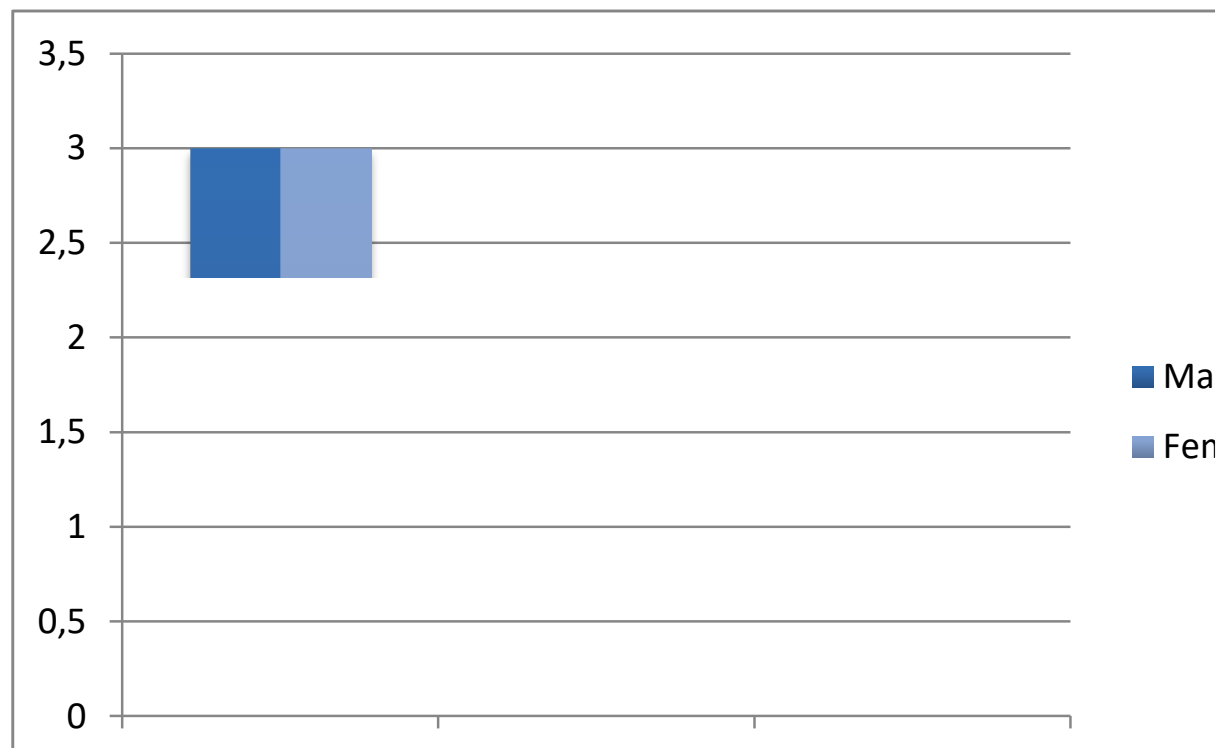

Fig. 1. Results of a series of experiments on inhalation effects of ozone-air mixture on rats at concentrations of 100, 500 and $2500 \mathrm{ppm}$ (male/female survivors).

The clinical picture of the effects of acute intoxication with ozone-air mixture in all experimental groups was characterized by the appearance of severe psychomotor agitation, nasal discharge (as a result of respiratory irritation), salivation, and lacrimation in the test animals at the early stages (up to 1 hour). Subsequently, the 2nd (500 ppm) and 3rd (2500 $\mathrm{ppm}$ ) groups registered rapid shallow breathing, and increased psychomotor agitation was gradually replaced by a depressed state (active attempts to "find a way out" alternated with short-term relaxation, the duration of which only increased further).

In the final stages (3-4 hours), some individuals of group 3 (2500 ppm) had a state of complete depression (no reaction to external stimuli), lack of motor activity, forced posture with the head thrown back, and gasping breath (rare gasps, gasps), which is the end stage of respiratory failure, followed by death as a result of respiratory arrest.

At the end of the study, there were deaths in 3 groups, namely, 2 males and 1 female died. The cause of death was respiratory arrest. Based on the results obtained, the average lethal concentration in the air (CL50/LC50) was calculated, the threshold value of which, according to the applied method [4], was $2500 \mathrm{ppm}$, which allows the studied ozone-air mixture to be classified as a hazard class 3 .

During the experiment, there were slight variations in sensitivity to the ozone-air mixture on the basis of gender (in group 3, 2 males and 1 female died).

In the study of histological preparations of the lungs and bronchi of rats that died from exposure to ozone-air mixture, focal desquamation of the bronchial epithelium was revealed. Hemodynamic disorders were also noted: due to the toxic effects of the ozone-air mixture, the porosity of the vessel walls increased, causing the exit of the liquid part of the blood into the perivascular space and erythrocyte diapedesis, the same was observed in the lumen of the alveoli. This pattern is a consequence of membrane pulmonary edema caused by toxic gases (in particular ozone), and developing the result of the initial increase in capillary permeability of the lungs. The interalveolar partitions are thickened in places due to capillary hyperemia. Arterial vessels are empty, and veins are filled with blood and expanded, and in both cases there is a general picture of fluid transudation into the perivascular space and erythrocyte diapedesis. 
When pathoanatomic examination of dead rats was observed the following picture. The lungs are non-sleeping, non-uniformly colored, mostly dark red (as a result of the action of chemical stimuli) with multiple foci of pale pink color that rise above the surrounding tissue and do not differ in consistency from it, and when pressed on them, crepitation (alveolar emphysema) is heard. From the surface of the incision and the bronchi, a foamy pinkish liquid is released, the pieces of the lungs do not sink in the water.

\subsection{Subchronic inhalation toxicity}

During the 90-day study of chronic inhalation toxicity, no intoxication was observed in all experimental groups $(250,125$, and $50 \mathrm{ppm})$, and there were no deaths. During the entire study, the overall condition of the animals did not change and, with slight fluctuations, corresponded to the control group in terms of the condition of the fur and skin, visible mucous membranes, feed and water consumption. When examining the eyes, the conjunctiva is pale pink, without bleeding. The cornea is transparent, without opacities.

The average daily rates of feed consumption by animals in the study groups (figure 2) differed slightly from the control group. Thus, in all experimental groups, there was a positive dynamics of feed consumption.

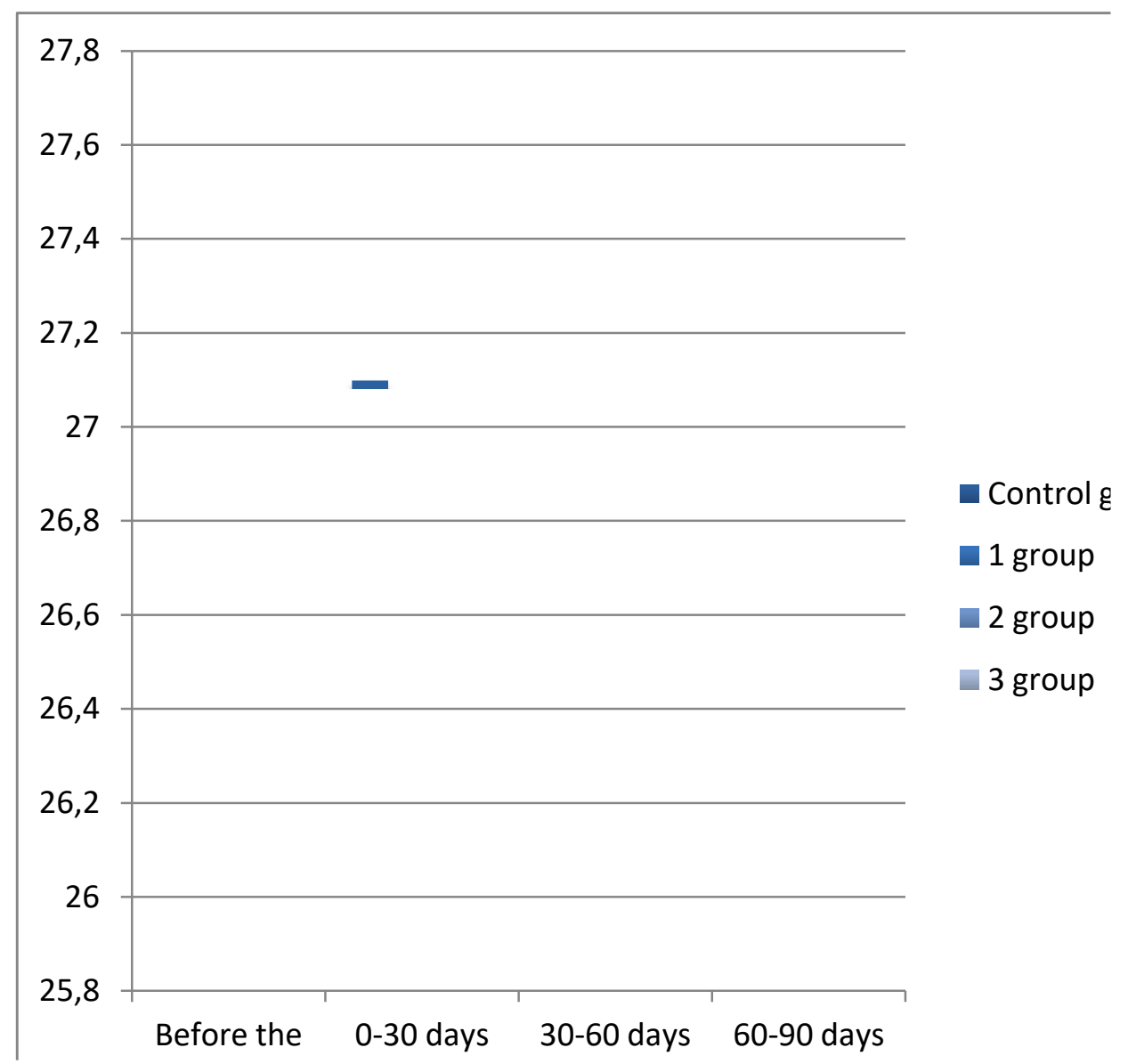

Fig. 2. Average daily rates of feed consumption by animals during the entire study period (90 days), grams. 
There were no significant differences in the dynamics of body weight in the control and experimental groups. During the study, the weight of the control group increased by $12.5 \%$ in males and $17.1 \%$ in females relative to the initial indicators. In the experimental groups, there was a slight slowdown in weight gain. Thus, in group A, the weight gain was $6.01 \%$ and $9.26 \%$, in group B, $7.8 \%$ and $10.06 \%$, and in group C, $6.6 \%$ and $9.1 \%$ for males and females, respectively. There were also minor gender differences in body weight dynamics. The results of animal weight control are shown in figure 3.

\section{0}

200

50

0

\section{Control 1 group 2 group 3 group group}

Control 1 group 2 group 3 \{ group

Fig. 3. Dynamics of rat body weight in the control and experimental groups against the background of a 90-day study of inhaled subchronic toxicity of the ozone-air mixture (on the left-before the start of the experiment, on the right - after the end).

When analyzing the results of hematological and biochemical analysis of rat blood (table 1), no statistically significant changes were observed in the test groups.

Table 1. Results of hematological study and biochemical analysis of rat blood against the background of 90-day study of inhalation chronic toxicity of ozone-air mixture.

\begin{tabular}{|c|c|c|c|c|}
\hline Indicators & Control & $\begin{array}{c}\text { Group 1 } \\
(250 \mathrm{ppm})\end{array}$ & $\begin{array}{c}\text { Group 2 } \\
(125 \mathrm{ppm})\end{array}$ & $\begin{array}{c}\text { Group 3 } \\
(50 \mathrm{ppm})\end{array}$ \\
\hline RBC, $10^{12} / 1$ & $5,31 \pm 0,19$ & $6,18 \pm 0,3$ & $5,91 \pm 0,27$ & $5,67 \pm 0,20$ \\
\hline WBC, $10^{9} / 1$ & $6,94 \pm 0,37$ & $6,97 \pm 0,23$ & $6,93 \pm 0,14$ & $6,7 \pm 0,36$ \\
\hline Rod-core neutrophils \% & $6,43 \pm 0,49$ & $6,9 \pm 0,80$ & $6,78 \pm 0,47$ & $6,54 \pm 0,60$ \\
\hline Segmentonuclear neutrophils \% & $24,1 \pm 2,98$ & $25,22 \pm 2,56$ & $25,14 \pm 3,3$ & $24,9 \pm 2,93$ \\
\hline Eosinophils, EO\% & $0,38 \pm 0,26$ & $0,39 \pm 0,40$ & $0,35 \pm 0,38$ & $0,37 \pm 0,21$ \\
\hline
\end{tabular}




\begin{tabular}{|c|c|c|c|c|}
\hline Basophils, BA\% & $0,21 \pm 0,02$ & $0,18 \pm 0,30$ & $0,15 \pm 0,01$ & $0,17 \pm 0,02$ \\
\hline Monocytes, MON\% & $2,5 \pm 0,53$ & $2,93 \pm 0,27$ & $2,65 \pm 0,56$ & $2,27 \pm 0,30$ \\
\hline Lymphocytes, LY\% & $54,2 \pm 2,93$ & $55,8 \pm 3,38$ & $55,3 \pm 2,96$ & $54,2 \pm 2,63$ \\
\hline Alanine aminotransferase IU/L & $59,1 \pm 3,87$ & $57,9 \pm 3,23$ & $58,4 \pm 2,96$ & $58,10 \pm 4,01$ \\
\hline Aspartate aminotransferase IU/L & $\begin{array}{c}141,8 \pm 12,3 \\
6\end{array}$ & $\begin{array}{c}140,7 \pm 12,9 \\
3 \\
\end{array}$ & $139,3 \pm 11,63$ & $139,7 \pm 13,05$ \\
\hline Crude protein, $\mathrm{g} / 1$ & $65,8 \pm 2,44$ & $66,3 \pm 3,01$ & $67,1 \pm 2,62$ & $66,4 \pm 2,14$ \\
\hline Albumins g/l & $31,02 \pm 0,65$ & $30,84 \pm 0,7$ & $30,27 \pm 1,03$ & $31,4 \pm 0,65$ \\
\hline Globulins g/l & $40,94 \pm 1,42$ & $41,63 \pm 1,4$ & $41,14 \pm 0,9$ & $40,87 \pm 1,36$ \\
\hline Glucose, mmol / 1 & $6,4 \pm 0,37$ & $6,1 \pm 0,32$ & $6,3 \pm 0,19$ & $6,45 \pm 0,3$ \\
\hline Creatinine, $\mathrm{mmol} / \mathrm{l}$ & $0,051 \pm 0,02$ & $0,048 \pm 0,02$ & $0,050 \pm 0,01$ & $0,047 \pm 0,01$ \\
\hline Urea, $\mathrm{mmol} / \mathrm{l}$ & $4,38 \pm 0,27$ & $4,41 \pm 0,21$ & $4,36 \pm 0,18$ & $4,17 \pm 0,32$ \\
\hline
\end{tabular}

Based on the results of studying the behavioral activity of rats in the "open field" test, a slight tendency of its activation was revealed in the experimental groups during the entire period of the study. It should be noted that the locomotor activity of laboratory animals has features [23] that directly depend on the type of their nervous activity. B. Kvist [24, 25] noted that such behavior features are associated with the profile of motor asymmetry of the brain.

Table 2. Indicators of orientation research behavior of rats in the "Open field" test.

\begin{tabular}{|c|c|c|c|c|}
\hline $\begin{array}{c}\text { Criteria for orientation } \\
\text { research behavior }\end{array}$ & Group 1 & Group 2 & Group 3 & Control group \\
\hline $\begin{array}{c}\text { Latency period of the 1st } \\
\text { move, sec. }\end{array}$ & $4,1 \pm 0,62$ & $4,0 \pm 0,37$ & $4,3 \pm 0,42$ & $3,9 \pm 0,56$ \\
\hline $\begin{array}{c}\text { The number of crossed } \\
\text { peripheral squares, units. }\end{array}$ & $17,9 \pm 0,95$ & $18,1 \pm 0,52$ & $18,2 \pm 0,76$ & $18,5 \pm 0,49$ \\
\hline $\begin{array}{c}\text { The number of crossed } \\
\text { central squares, units. }\end{array}$ & $1,9 \pm 0,13$ & $2,0 \pm 0,23$ & $2,2 \pm 0,12$ & $2,6 \pm 0,35$ \\
\hline $\begin{array}{c}\text { Number of peripheral } \\
\text { racks, units. }\end{array}$ & $2,9 \pm 0,17$ & $3,2 \pm 0,11$ & $3,1 \pm 0,26$ & $2,9 \pm 0,19$ \\
\hline $\begin{array}{c}\text { Number of central racks, } \\
\text { units. }\end{array}$ & $0,4 \pm 0,13$ & $0,6 \pm 0,09$ & $0,7 \pm 0,11$ & $0,6 \pm 0,15$ \\
\hline $\begin{array}{c}\text { Climbing into the hole, } \\
\text { units. }\end{array}$ & $5,9 \pm 0,3$ & $6,2 \pm 0,41$ & $6,7 \pm 0,24$ & $6,9 \pm 0,4$ \\
\hline Grooming, units. & $2,6 \pm 0,3$ & $2,1 \pm 0,17$ & $2,5 \pm 0,24$ & $2,3 \pm 0,25$ \\
\hline Boluses, units. & $0,9 \pm 0,4$ & $0,7 \pm 0,2$ & $0,7 \pm 0,1$ & $0,6 \pm 0,1$ \\
\hline
\end{tabular}




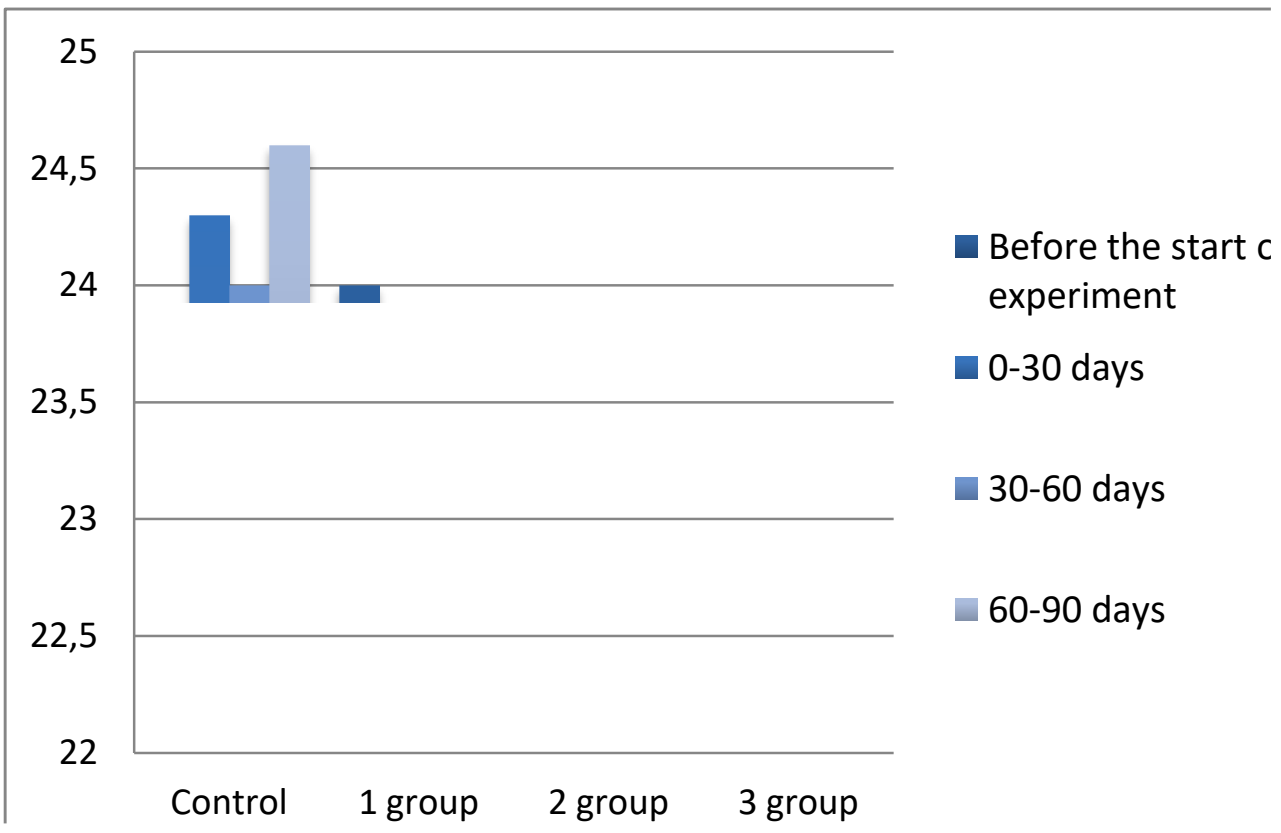

Fig. 4. Dynamics of the main activity level of rats throughout the experiment.

\section{Conclusions}

Thus, as a result of testing the ozone-air mixture obtained by a portable standalone ozone generator for acute inhalation toxicity, deaths were observed in the 3rd experimental group for 4 hours $(2500 \mathrm{ppm})$. Of the 6 rats tested, 3 individuals died, including 2 males and 1 female, and death occurred as a result of respiratory arrest. The average lethal concentration in the air (CL50/LC50) was set with a threshold of $2500 \mathrm{ppm}$. The obtained data, according to the state standard 32646-2014 "Acute inhalation toxicity - method for determining the class of acute toxicity (ATS method)", allow us to classify the studied ozone-air mixture as a class 3 hazard.

Based on the results of the study of subchronic inhalation toxicity of the ozone-air mixture, it was determined that its exposure to doses of 250, 125 and 50 ppm for 6 hours a day for 13 weeks does not cause intoxication and/or death in outbred Wistar rats. In the experimental groups, the dynamics of body weight and feed consumption remained unchanged relative to the control group.

\section{References}

1. D. Apuzzo, C. Giotti, et al., Functional Neurology 29(1), 31-39 (2014)

2. A.D. Chernyshyova, Bulletin of Siberian Medicine 8(3), 117-120 (2019) https://doi.org/10.20538/1682-0363-2009-3-117-120

3. S. Kist, M. Kollmuss, et al., Clinical Oral Investigations 21, 995- 1005 (2017)

4. N. Braidy, M. Izadi, et al., J. Cell. Physiol. 233 (4), 2705 (2018)

5. G.á., Borges, S.T. Elias, et al., J. Craniomaxillofac. Surg. 45 (3), 364-370 (2017)

6. R. Noites, C. Pina-Vaz, et al., BioMed Research International, 592423 (2014)

7. M. Perri, C. Grattacaso, et al., RadiolMed. 120(10), 941-950 (2015) 
8. M.N. Rojas-Valencia, In: A. Méndez-Vilas (ed.) Science Against Microbial Pathogens: Communicating Current Research and Technological Advances. Badajoz: Formatex, 263- 71 (2011)

9. Shayne Cox Gad. Preclinical Development Handbook, 1329 (Toxicology, North Carolina, 2007) DOI: 10.1002/9780470249055

10. A. Zambello, B. Fara, et al., Rivista di Neuroradiologia 5, 123-127 (2006)

11. S.K. Anand, A.V. Ebenezar, et al., Journal of Clinical and Diagnostic Research 9, ZC04- 6 (2015)

12. T. Boch, C. Tennert, et al., Clinical Oral Investigations 20, 1733-9 (2016)

13. J. Hidalgo-Tallón, S. Menéndez-Cepero, et al., The Journal of Alternative and Complementary Medicine 19, 3, 238-242 (2013)

14. M. Copello, S. Menéndez, and F. Hernández, Ozone: Science \& Engineering 34, 6, 476-483 (2012)

15. V. Bocci, I. Zanardi, E. Borrelli, and V. Travagli, Journal of Pharmacy and Pharmacology 64, 4, 482-489 (2011)

16. V. A. Bocci, I. Zanardi, and V. Travagli, Journal of Translational Medicine 9, 1, 66 (2011)

17. E. Agathokleous, R. G. Belz, et al., Science of The Total Environment 649, 61-74 (2019)

18. B. Clavo, N. Santana-Rodríguez, et al., Evidence-Based Complementary and Alternative Medicine 10.1155/2018/7931849, 1-11 (2018)

19. F. Mehraban, A. Seyedarabi, et al., International Journal of Biological Macromolecules 119, 1276-1285 (2018)

20. N. Santana-Rodríguez, P. Llontop, et al., The Annals of Thoracic Surgery 104, 2, 458464 (2017)

21. E. Gonzalez-Guevara, et al., Inhalation Toxicology. 26, (8), 485-491 (2014)

22. B. Kilburg-Basnyat, et al., Toxicological Sciences. 163, (2), 466-477 (2018)

23. T. Archer, A. Fredriksson, et al., Scandinavian Journal of Psychology 28, 3, 242-249 (2008)

24. B. Kvist, Of Mice and Women 10.1016/B978-0-12-102590-8.50036-2, 351-366 (1992)

25. B. Kvist, Scandinavian Journal of Psychology 27, 1, 58-63 (2008) 